\title{
A two-phase bromination process using tetraalkylammonium hydroxide for the practical synthesis of $\alpha$-bromolactones from lactones
}

\author{
Yuki Yamamoto ${ }^{1}$, Akihiro Tabuchi ${ }^{1}$, Kazumi Hosono ${ }^{2}$, Takanori Ochi ${ }^{2}$, Kento Yamazaki ${ }^{2}$, \\ Shintaro Kodama ${ }^{1}$, Akihiro Nomoto ${ }^{* 1}$ and Akiya Ogawa ${ }^{* 1}$
}

\author{
Full Research Paper

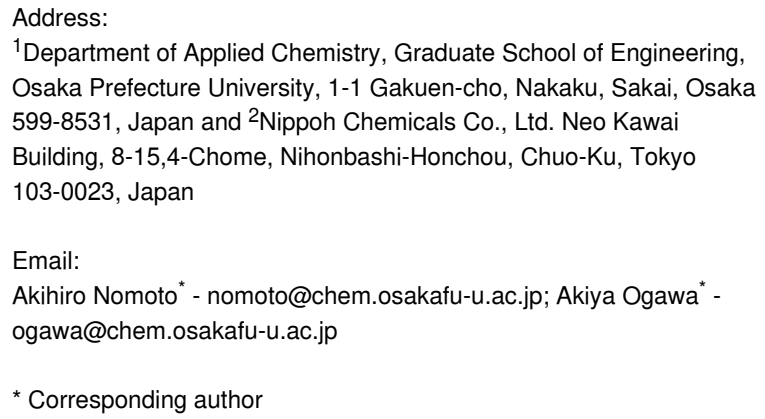

${ }^{1}$ Department of Applied Chemistry, Graduate School of Engineering, Osaka Prefecture University, 1-1 Gakuen-cho, Nakaku, Sakai, Osaka 599-8531, Japan and ${ }^{2}$ Nippoh Chemicals Co., Ltd. Neo Kawai Building, 8-15,4-Chome, Nihonbashi-Honchou, Chuo-Ku, Tokyo 103-0023, Japan

Email:

Akihiro Nomoto* - nomoto@chem.osakafu-u.ac.jp; Akiya Ogawa* -

ogawa@chem.osakafu-u.ac.jp

${ }^{*}$ Corresponding author \\ Keywords: \\ $\alpha$-bromolactone; metal-free; one-pot operation; tetraalkylammonium \\ hydroxide; two-phase system
}

Open Access

Beilstein J. Org. Chem. 2021, 17, 2906-2914.

https://doi.org/10.3762/bjoc.17.198

Received: 30 September 2021

Accepted: 24 November 2021

Published: 09 December 2021

Associate Editor: D. Y.-K. Chen

(๑) 2021 Yamamoto et al.; licensee Beilstein-Institut. License and terms: see end of document.

\begin{abstract}
A simple and efficient method for $\alpha$-brominating lactones that affords $\alpha$-bromolactones under mild conditions using tetraalkylammonium hydroxide $\left(\mathrm{R}_{4} \mathrm{~N}^{+} \mathrm{OH}^{-}\right)$as a base was developed. Lactones are ring-opened with $\mathrm{Br}_{2}$ and a substoichiometric amount of $\mathrm{PBr}_{3}$, leading to good yields of the corresponding $\alpha$-bromocarboxylic acids. Subsequent intramolecular cyclization over $1 \mathrm{~h}$ using a two-phase system $\left(\mathrm{H}_{2} \mathrm{O} / \mathrm{CHCl}_{3}\right)$ containing $\mathrm{R}_{4} \mathrm{~N}^{+} \mathrm{OH}^{-}$afforded $\alpha$-bromo lactones in good yields. This method can be applied at the $10 \mathrm{mmol}$ scale using simple operations. $\alpha$-Bromo- $\delta$-valerolactone, which is extremely reactive and difficult to isolate, could be isolated and stored in a freezer for about one week using the developed method. Optimizing the solvent for environmentally friendly large-scale syntheses revealed that methyl ethyl ketone (MEK) was as effective. In addition, in situ-generated $\alpha$-bromo- $\delta$-valerolactone was directly converted into a sulfur-substituted functional lactone without difficulty by reacting it with a sulfur nucleophile in one pot without isolation. This new bromination system is expected to facilitate the industrial use of $\alpha$-bromolactones as important intermediates.
\end{abstract}

\section{Introduction}

Lactones are important heterocycles in the organic chemistry, materials science, and medicinal chemistry fields, and bromolactones are important synthetic intermediates for selectively,

effectively, and practically introducing lactone units into organic molecules [1-18]. Among brominated lactones, the $\alpha$-bromolactone, in which the bromine atom is located at the 
$\alpha$-position relative to the carbonyl group, is the most versatile synthetic intermediate [19-28]. $\alpha$-Bromolactones are widely used as synthetic intermediates for functional materials and pharmaceuticals, as well as initiators in atom-transfer living radical polymerization (ATRP) reactions and functional polymer synthesis [29-34].

Although $\alpha$-bromo- $\gamma$-butyrolactone, which is a five-membered lactone, is easily accessible from the five-membered lactone by some bromination methods [35,36], the bromination method for the six-membered lactone, $\delta$-valerolactone $(\mathbf{1 a})$, has been limited. The main process for the bromination of $\delta$-valerolactone (1a) was treating the lactone with lithium diisopropylamide (LDA) at $-78{ }^{\circ} \mathrm{C}$ to first generate the corresponding enolate, trapping it with trimethylsilyl chloride ( $\mathrm{TMSCl})$ to form the enol silyl ether, followed by reaction with bromine (Scheme 1a) $[37,38]$. While the industrial demand for $\alpha$-bromolactones has grown in recent years, the above-mentioned laboratory-level synthetic methods are not suitable for scale-up because LDA, TMSCl, and enol silyl ethers are sensitive to moisture and air, as well as being expensive for large-scale syntheses. Therefore, the development of an innovative, cost-effective method for the production of $\alpha$-bromolactones in large quantities is highly desirable.

In this study, we aimed to establish a new method for the synthesis of $\alpha$-bromolactones and successfully developed an innovative synthetic method that relies on a two-phase reaction system. Specifically, lactones are ring-opened and converted into dibromocarboxylic acids when treated with $\mathrm{Br}_{2}$ and a substoichiometric amount of $\mathrm{PBr}_{3}$. Subsequent treatment of these carboxylic acids with a base leads to the corresponding $\alpha$-bromolactones through ring-closing reactions that involve the elimination of $\mathrm{HBr}$; notably, ring-closure is successfully promoted in a two-phase system (Scheme 1b). Furthermore, we also report the simple one-pot transformations of lactone derivatives using $\alpha$-bromolactones as key intermediates.

\section{Results and Discussion}

We begin by first discussing the properties and stabilities of industrially important five- and six-membered lactones. $\gamma$-Butyrolactone and its $\alpha$-brominated derivative are both stable at room temperature; $\alpha$-bromo- $\gamma$-butyrolactone is readily synthesized by brominating the five-membered lactone under basic conditions. In sharp contrast, the corresponding six-membered $\alpha$-bromo- $\delta$-valerolactone has a more-distorted ring and is extremely unstable, even at room temperature [39-41]. In fact, it must be stored in a freezer because ring-opening polymerization and ring-contraction reactions occur readily at room temperature (see Supporting Information File 1). Therefore, in this study, we chose unstable $\delta$-valerolactone (1a) as a model compound during the development of a new and innovative method for the synthesis of $\alpha$-bromolactones, and investigated the reaction conditions in detail.

We first examined the Hell-Volhard-Zelinsky-type ringopening reaction of $\mathbf{1 a}$ (Table 1). In this reaction, the corresponding acid bromide is formed in situ by heating with $\mathrm{Br}_{2}$ and

a) general procedure for $\alpha$-brominating $\delta$-valerolactone

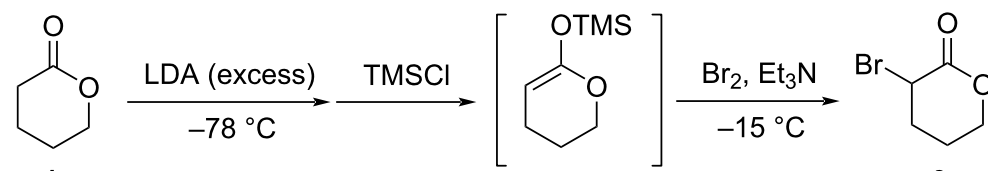

1a

b) this work
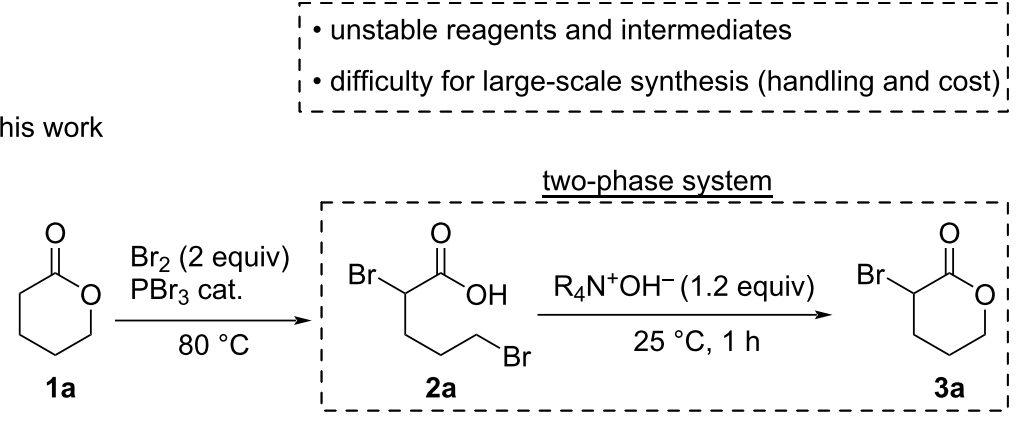

- stable reagents and intermediates

- easy manipulation and gram-scale synthesis 
Table 1: Ring-opening reactions of lactones with $\mathrm{Br}_{2}$ in the presence of a substoichiometric amount of $\mathrm{PBr}_{3}{ }^{\mathrm{a}}$.

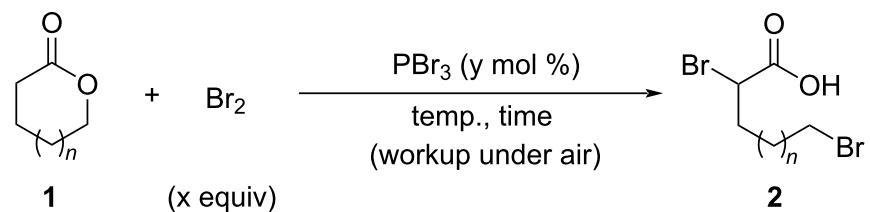

\begin{tabular}{llllllll}
\hline Entry & $n$ & $\mathbf{1}(\mathrm{mmol})$ & $\mathrm{Br}_{2}$ (equiv) & $\mathrm{PBr}_{3}(\mathrm{~mol} \%)$ & Temp. $\left({ }^{\circ} \mathrm{C}\right)$ & Time $(\mathrm{h})$ & Yield $\mathbf{2}(\%)$ \\
\hline 1 & $\mathbf{1 a}: n=1$ & 5 & 2.0 & 5 & 80 & 24 & 2a: 90 \\
2 & $\mathbf{1 a}: n=1$ & 5 & 2.0 & - & 80 & 24 & $\mathbf{2 a}: 1$ \\
3 & $\mathbf{1 a}: n=1$ & 31 & 2.0 & 10 & 80 & 24 & $\mathbf{2 a}: 89$ \\
4 & $\mathbf{1 b}: n=0$ & 31 & 2.0 & 10 & 90 & 24 & $\mathbf{2 b :} 76$ \\
5 & $\mathbf{1 C}: n=2$ & 31 & 2.0 & 10 & 90 & 24 & 2c: 70 \\
\hline
\end{tabular}

aYields were determined by ${ }^{1} \mathrm{H}$ NMR spectroscopy using 1,3,5-trioxane as an internal standard.

a substoichiometric amount of $\mathrm{PBr}_{3}$; the acid bromide is then converted into 2,5-dibromopentanoic acid (2a) via hydrolysis during the workup under open-air. Lactone $1 \mathrm{a}(5 \mathrm{mmol})$ was allowed to react with $\mathrm{Br}_{2}$ (2.0 equiv) and $\mathrm{PBr}_{3}(5 \mathrm{~mol} \%)$ at $80{ }^{\circ} \mathrm{C}$ for $24 \mathrm{~h}$, with subsequent hydrolysis successfully affording in $\mathbf{2 a}$ in $90 \%$ yield (Table 1, entry 1 ). In the absence of a substoichiometric amount of $\mathrm{PBr}_{3}$, the transformation of $\mathbf{1 a}$ to $\mathbf{2 a}$ hardly proceeded (Table 1, entry 2). $\mathbf{2 a}$ was obtained in $89 \%$ yield when this protocol was used on a $31 \mathrm{mmol}$ scale (Table 1, entry 3). $\gamma$-Butyrolactone (1b) and $\varepsilon$-caprolactone (1c) were also converted into the corresponding dibromocarboxylic acids $\mathbf{2 b}$ and $\mathbf{2 c}$ in yields of $76 \%$ and $70 \%$, respectively (Table 1 , entries 4 and 5).
Since we successfully synthesized carboxylic acid $\mathbf{2 a}$ from lactone 1a in good yield, we next investigated the ring-closing reaction of 2a. Various acids and bases (PTSA, hydrochloric acid, $\mathrm{NaOH}, \mathrm{KOH}$, and $\mathrm{NaHCO}_{3}$ ) were used to promote the intramolecular cyclization of $\mathbf{2 a}$; however, no reaction was observed using any of these acids/bases. Interestingly, 2a was converted into $3 \mathrm{a}$ in very low yield when 1.2 equiv of $n-\mathrm{Bu}_{4} \mathrm{~N}^{+} \mathrm{F}^{-}$ was used, despite $n$ - $\mathrm{Bu}_{4} \mathrm{~N}^{+} \mathrm{F}^{-}$itself being less basic than the other bases (Scheme 2a) [42,43]. These results suggest that the properties of the counter cation may be important for the intramolecular cyclization of 2a. Based on this observation, we next examined $n-\mathrm{Bu}_{4} \mathrm{~N}^{+} \mathrm{OH}^{-}$, a more-basic $\mathrm{R}_{4} \mathrm{~N}^{+} \mathrm{X}^{-}$system, for the ring-closure of $\mathbf{2 a}$. Surprisingly, the reaction proceeded<smiles>O=C(O)C(Br)CCCBr</smiles>
$\underset{\operatorname{THF}(1 \mathrm{M}), 25^{\circ} \mathrm{C}, 1 \mathrm{~h}}{\stackrel{n-\mathrm{Bu}_{4} \mathrm{~N}^{+} \mathrm{F}^{-}}{(1.2 \text { equiv })}}$ $2 a$<smiles>O=C(O)C(Br)CCCBr</smiles>
$\underset{\mathrm{CH}_{3} \mathrm{CN}(0.2 \mathrm{M}), 25^{\circ} \mathrm{C}, 43 \mathrm{~h}}{\stackrel{n-\mathrm{Bu}_{4} \mathrm{~N}^{+} \mathrm{OH}^{-}}{(1.2 \text { equiv })}}$<smiles>O=C1OCCCC1Br</smiles>

3a $(52 \%)$

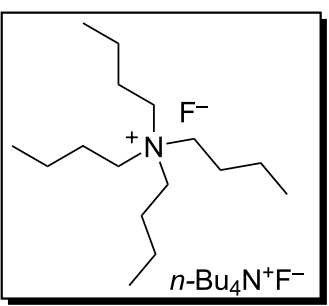

(a)

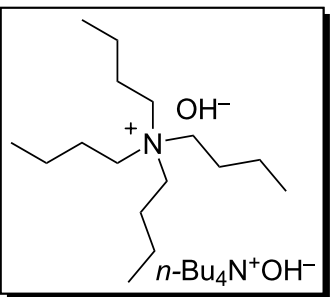

(b) 
smoothly to give $\alpha$-bromo- $\delta$-valerolactone (3a) in $52 \%$ yield in $43 \mathrm{~h}$ (Scheme 2b). However, further extending the reaction time to $72 \mathrm{~h}$ resulted in a dramatically lower yield of $\mathbf{3 a}(8 \%)$, most likely because 3a is unstable to base at room temperature and may decompose or polymerize (see Supporting Information File 1).

To avoid decomposition or polymerization, 3a produced in situ by the intramolecular cyclization of $\mathbf{2 a}$ should be separated immediately from the reaction mixture containing $n-\mathrm{Bu}_{4} \mathrm{~N}^{+} \mathrm{OH}^{-}$. Tetraalkylammonium salts are used as phasetransfer catalysts as they are soluble in both organic solvents and water. With these properties in mind, we next investigated the ring-closure of $\mathbf{2 a}$ using a two-phase $\mathrm{CHCl}_{3} / \mathrm{H}_{2} \mathrm{O}$ system (Table 2). Intramolecular cyclization of the salt forms $\mathbf{3 a}$, which is extracted into the organic layer due to its low solubility in water. Because $n-\mathrm{Bu}_{4} \mathrm{~N}^{+} \mathrm{OH}^{-}$is less-soluble in organic solvents than water, 3a is phase-separable from the base. To our delight, 2a was smoothly converted into $\mathbf{3 a}$ in $74 \%$ yield in this twophase system, with the reaction time successfully reduced to $1 \mathrm{~h}$ (Table 2, entries 1-5). The use of a co-solvent to increase the solubility of 2a was investigated in detail; DMSO was found to be the most effective solvent, with $3 \mathbf{a}$ produced in $82 \%$ yield (Table 2, entries 5-12).

Table 2: Optimizing the intramolecular cyclization of $\mathbf{2 a}$ in a two-phase
system ${ }^{\mathrm{a}}$.

aYields were determined by ${ }^{1} \mathrm{H}$ NMR spectroscopy using 1,3,5-trioxane as an internal standard.

We next optimized the base used to cyclize $\mathbf{2 a}$ in the two-phase system under the optimized conditions (entry 10, Table 2), the results of which are summarized in Table 3. The use of tetraalkylammonium hydroxides with longer alkyl chains tended to increase the yield of $\mathbf{3 a}$ (Table 3, entries 1-5), while the use of diisopropylethylamine, triethylamine, $\mathrm{DBU}$, or $\mathrm{Cs}_{2} \mathrm{CO}_{3}$ was

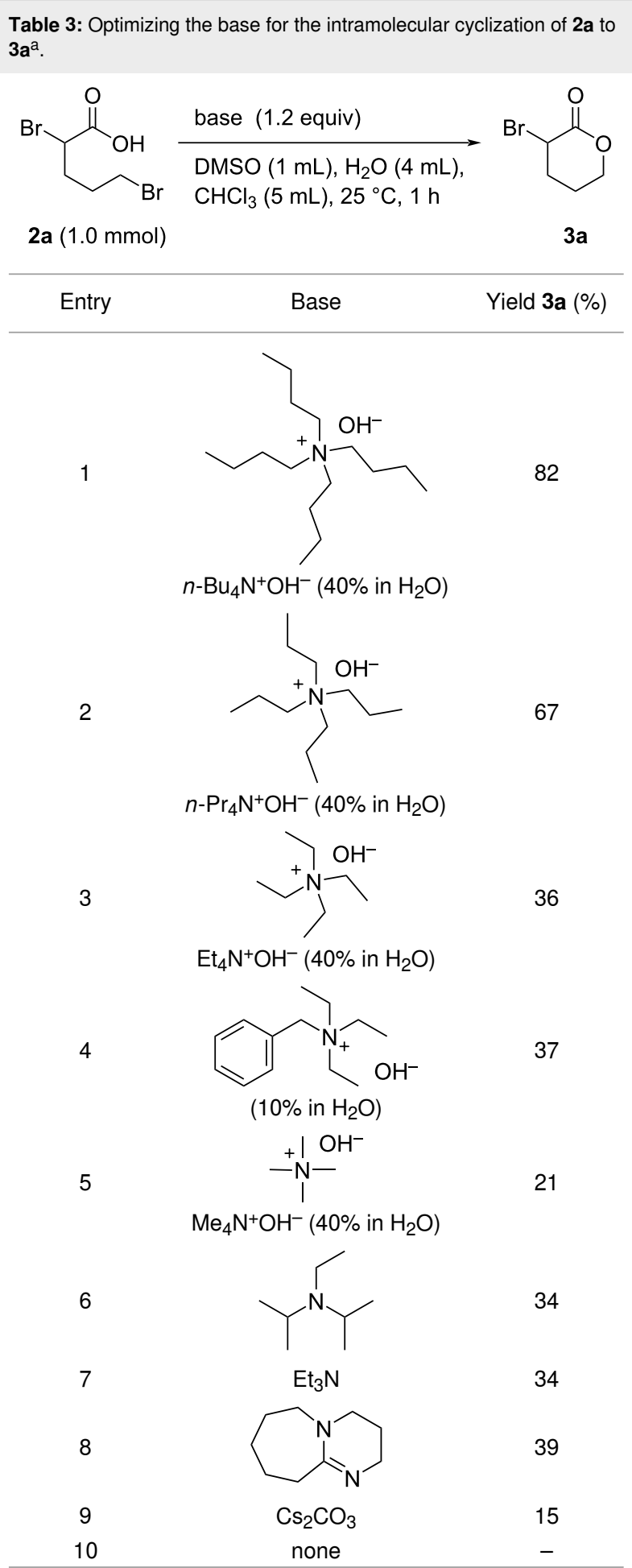

aYields were determined by ${ }^{1} \mathrm{H}$ NMR spectroscopy using 1,3,5-trioxane as an internal standard. 
less effective (Table 3, entries 6-9); furthermore, the reaction did not proceed in the absence of a base (Table 3, entry 10). This investigation revealed that medium-chain tetraalkylammonium hydroxides, namely $n$ - $\mathrm{Bu}_{4} \mathrm{~N}^{+} \mathrm{OH}^{-}$and $n-\mathrm{Pr}_{4} \mathrm{~N}^{+} \mathrm{OH}^{-}$, effectively transform $\mathbf{2 a}$ into $\mathbf{3 a}$ through intramolecular cyclization.

We next investigated the effect of the size of the lactone ring on the $\alpha$-bromination reaction in this two-phase system. Table 4 shows that $\mathbf{2 a}$ and $\mathbf{2 b}$ were transformed to $\mathbf{3 a}$ and $\mathbf{3 b}$ in good yields, but $2 \mathbf{c}$ did not react under these conditions due to the entropic cost associated with forming a seven-membered ring. Lactones $\mathbf{3 a}$ and $\mathbf{3 b}$ were obtained in good yields even when $n-\mathrm{Pr}_{4} \mathrm{~N}^{+} \mathrm{OH}^{-}$was used as the base [44].

Table 4: Reaction scope for the the intramolecular cyclization of 2 in a two-phase system ${ }^{\mathrm{a}}$.

$$
\underbrace{\mathrm{OH}}_{n} \frac{\begin{array}{l}
\mathrm{CH}_{3} \mathrm{CN}(1 \mathrm{~mL}), \mathrm{H}_{2} \mathrm{O}(4 \mathrm{~mL}), \\
\mathrm{CHCl}_{3}(5 \mathrm{~mL}), 25^{\circ} \mathrm{C}, 1 \mathrm{~h}
\end{array}}{\stackrel{\mathrm{O}}{\mathrm{O}} \mathrm{CH}_{\mathrm{H}}}
$$

2

\begin{tabular}{llll}
\hline Entry & $n$ & Base & Yield $\mathbf{3}(\%)$ \\
\hline 1 & 2a: $n=1$ & $n-\mathrm{Bu}_{4} \mathrm{~N}^{+} \mathrm{OH}^{-}$ & 3a: 74 \\
& & $n-\mathrm{Pr}_{4} \mathrm{~N}^{+} \mathrm{OH}^{-}$ & 3a: $75^{\mathrm{b}}$ \\
2 & 2b: $n=0$ & $n-\mathrm{Bu}_{4} \mathrm{~N}^{+} \mathrm{OH}^{-}$ & 3b: 69 \\
& & $n-\mathrm{Pr}_{4} \mathrm{~N}^{+} \mathrm{OH}^{-}$ & 3b: $73(61)$ \\
& & $n-\mathrm{Bu}_{4} \mathrm{~N}^{+} \mathrm{OH}^{-}$ & 3c: trace \\
& 2c: $n=2$ & $n-\mathrm{Pr}_{4} \mathrm{~N}^{+} \mathrm{OH}^{-}$ & 3c: trace \\
\hline
\end{tabular}
as an internal standard (isolated yield). ${ }^{b}$ See reference [44].

While the developed two-phase $\mathrm{CHCl}_{3} / \mathrm{H}_{2} \mathrm{O}$ system performed well for the syntheses of $\alpha$-bromolactones, the use of $\mathrm{CHCl}_{3}$ as
aYields were determined by ${ }^{1} \mathrm{H}$ NMR spectroscopy using 1,3,5-trioxane the reaction solvent should ideally be avoided because it is toxic and an environmental pollutant. Therefore, we further optimized the solvent combination to construct an ecofriendlier reaction system (Table 5). Various solvents were used as the organic layer instead of $\mathrm{CHCl}_{3}$, with 3a produced in good yield using methyl ethyl ketone (MEK) as the solvent (Table 5, entries 1-5). Although the use of other ketones as solvents also afforded 3a in moderate yields, MEK proved to be the most suitable replacement for $\mathrm{CHCl}_{3}$ (Table 5, entries $5-8)$.

Table 5: Optimizing the organic solvent in the two-phase system ${ }^{a}$

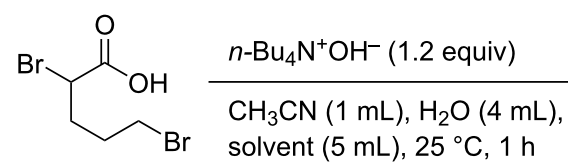<smiles>O=C1OCCCC1Br</smiles>

$2 \mathbf{a}(1.0 \mathrm{mmol})$ $3 a$

\begin{tabular}{lll}
\hline Entry & Solvent & Yield 3a (\%) \\
\hline 1 & $\mathrm{CHCl}_{3}$ & 74 \\
2 & $\mathrm{FC}-72$ & 56 \\
3 & $\mathrm{BTF}$ & 43 \\
4 & 2-bromopropane & 33 \\
5 & MEK & 75 \\
6 & acetylacetone & 64 \\
7 & 3-methyl-2-butanone & 55 \\
8 & pinacolone & 49 \\
\hline
\end{tabular}

aYields were determined by ${ }^{1} \mathrm{H}$ NMR spectroscopy using 1,3,5-trioxane as an internal standard.

This environmentally friendly procedure was used to synthesize other lactones. For instance, this method was used to prepare $\mathbf{3 b}$ from $\mathbf{2 b}$ in $84 \%$ yield on a $10 \mathrm{mmol}$ scale (Scheme 3a). Furthermore, this system also provided 2,2-<smiles>O=C(O)C(Br)CCBr</smiles>

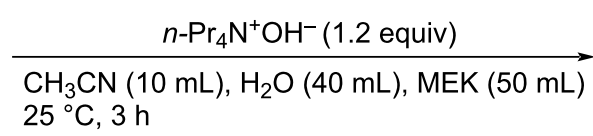
2b (10 mmol)<smiles>O=C(O)C(CCBr)(c1ccccc1)c1ccccc1</smiles>

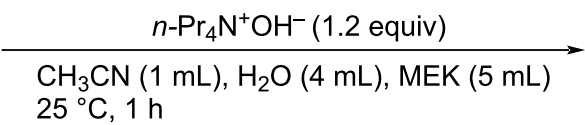
2d $(1.0 \mathrm{mmol})$<smiles>O=C1OCCC1Br</smiles>

3b, $84 \%$ (64\%)<smiles>O=C1OCCC1(c1ccccc1)c1ccccc1</smiles>

3d, $78 \%(72 \%)$ 
diphenyl- $\gamma$-butyrolactone (3d), which bears two phenyl groups at the $\alpha$-position, in $78 \%$ yield (Scheme $3 b$ ).

$\alpha$-Bromolactones were obtained without any handling difficulties using our developed system, with synthesis scale-up tolerated under mild conditions. To facilitate the construction of various functional scaffolds using this system, lactones were subsequently $\alpha$-functionalized via the corresponding $\alpha$-bromolactones using this two-phase system. Interestingly, $\mathbf{3 b}$ synthesized using this method was smoothly substituted at the $\alpha$-position with benzenethiol (4) in the presence of $\mathrm{K}_{2} \mathrm{CO}_{3}$ to afford the unsymmetrically functionalized sulfide $\mathbf{5}$ in $86 \%$ yield; $\mathbf{5}$ is a precursor to some pharmaceutical cores (Scheme 4) [45-48].

However, $\boldsymbol{\alpha}$-bromo- $\delta$-valerolactone (3a) was extremely unstable under ambient conditions, and its purity quickly deteriorated even when stored in a freezer with shading (see Supporting Information File 1), resulting in trace amounts of $\alpha$-functionalized lactones using the above-mentioned two-step method. Hence, we focused on sequential nucleophilic substitution in a two-phase system based on this bromination protocol. After ring-closing $\mathbf{2 a}$, the generated $\alpha$-bromolactone $3 \mathbf{a}$ was extracted into the organic layer, whereas the formed $n-\mathrm{Bu}_{4} \mathrm{~N}^{+} \mathrm{Br}^{-}$dissolved in both the aqueous and organic layers. $N-\mathrm{Bu}_{4} \mathrm{~N}^{+} \mathrm{Nu}^{-}$is formed when $\mathrm{Na}^{+} \mathrm{Nu}^{-}\left(\mathrm{Nu}^{-}\right.$: nucleophile) is added to the reaction mixture, which is then phase-transferred into the organic phase, with subsequent nucleophilic substitution at the $\alpha$-position of 3a proceeding directly to produce a variety of $\alpha$-substi- tuted lactones, along with the regeneration of $n-\mathrm{Bu}_{4} \mathrm{~N}^{+} \mathrm{Br}^{-}$ (Scheme 5).

To demonstrate the applicability of this protocol, we investigated the synthesis of 2-phenylthio- $\alpha$-valerolactone (6). Carboxylic acid $2 \mathrm{a}(2.0 \mathrm{mmol})$ directly reacted with $n-\mathrm{Bu}_{4} \mathrm{~N}^{+} \mathrm{OH}^{-}$ (1.2 equiv) and $\mathrm{PhS}^{-} \mathrm{Na}^{+}$in the two-phase system under the optimized conditions for the synthesis of $\alpha$-bromolactones, and $\mathbf{6}$ was successfully obtained in $72 \%$ yield (Scheme 6 ). These results demonstrate that this novel system facilitates the easy syntheses of functional molecules via $\alpha$-bromolactones as key synthetic intermediates.

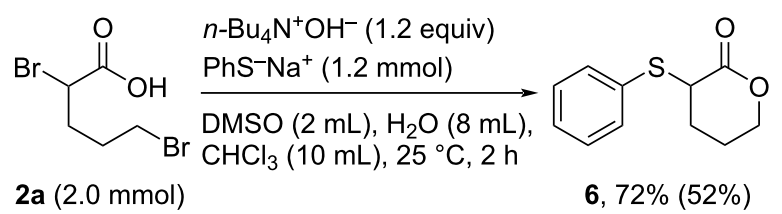

Scheme 6: One-pot synthesis of 2-phenylthio- $\alpha$-valerolactone 6 .

\section{Conclusion}

In this study, we developed a facile and efficient method for $\alpha$-brominating lactones using tetraalkylammonium hydroxide $\left(\mathrm{R}_{4} \mathrm{~N}^{+} \mathrm{OH}^{-}\right)$as the base under mild conditions. Lactones were ring-opened with $\mathrm{Br}_{2}$ and a substoichiometric amount of $\mathrm{PBr}_{3}$, which led to the corresponding $\alpha$-bromocarboxylic acids in

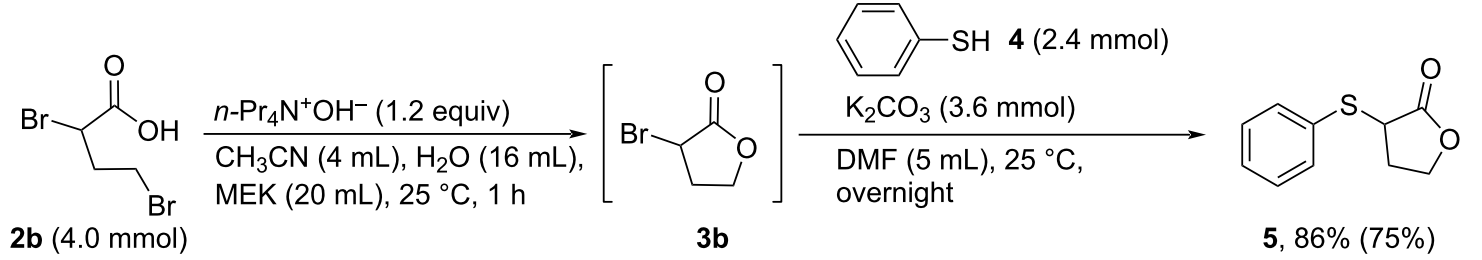

Scheme 4: Synthesis of unsymmetrically functionalized sulfide $\mathbf{5}$ via the two-phase system-promoted intramolecular cyclization of $\mathbf{2 b}$.
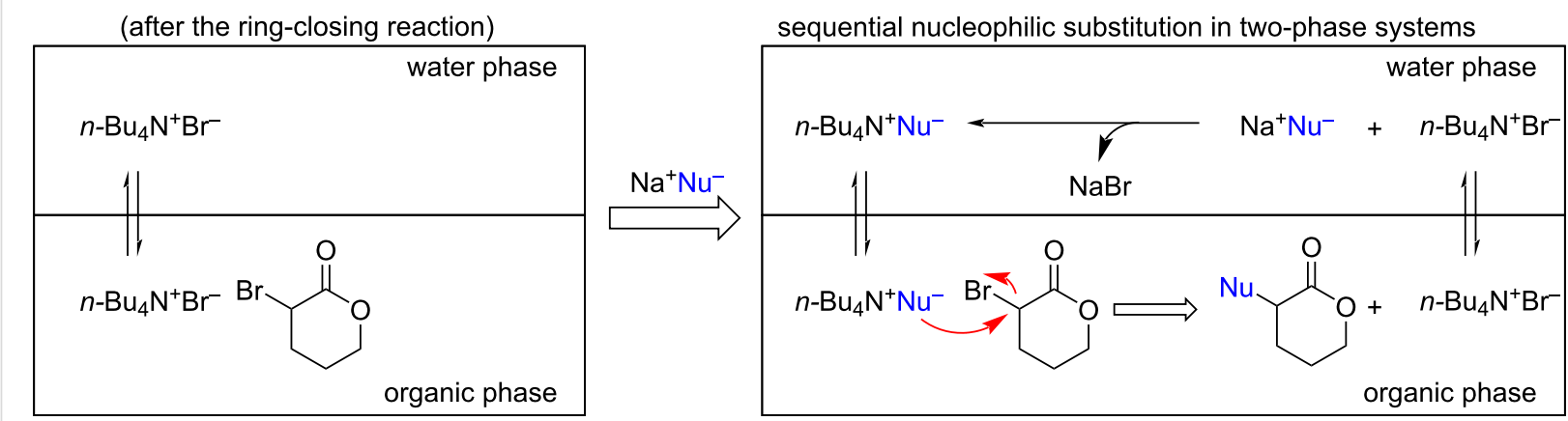

Scheme 5: Sequential nucleophilic substitution in the two-phase system. 
good yields. These carboxylic acids subsequently underwent intramolecular cyclization in $1 \mathrm{~h}$ using a two-phase system $\left(\mathrm{H}_{2} \mathrm{O} / \mathrm{CHCl}_{3}\right)$ with $\mathrm{R}_{4} \mathrm{~N}^{+} \mathrm{OH}^{-}$to afford $\alpha$-bromolactones in excellent yields. The use of methyl ethyl ketone (MEK) in the two-phase system led to an eco-friendly system amenable to large-scale synthesis. Furthermore, the $\alpha$-bromolactones generated in situ by this method were transformed into functional molecules, such as $\alpha$-thiolated lactones, in good yields without any handling difficulties. We expect that this new bromination system will lead to the use of various $\alpha$-bromolactones as synthetic intermediates in organic chemistry.

\section{Experimental}

General comments. Unless otherwise stated, all starting materials and catalysts were purchased from commercial sources and used without further purification. All solvents were used without distillation. ${ }^{1} \mathrm{H}$ NMR spectra were recorded on a JEOL JNM-ECS400 (400 MHz) FT NMR system or a JEOL JNMECX400 (400 MHz) FT NMR system in $\mathrm{CDCl}_{3}$ with $\mathrm{Me}_{4} \mathrm{Si}$ as an internal standard. ${ }^{13} \mathrm{C}\left\{{ }^{1} \mathrm{H}\right\}$ NMR spectra were recorded on a JEOL JNM-ECX400 (100 MHz) FT NMR or JEOL JNMECS400 (100 MHz) FT NMR system in $\mathrm{CDCl}_{3}$.

Ring-opening reaction of $\delta$-valerolactone (1a) with $\mathrm{Br}_{2}$ in the presence of a catalytic amount of $\mathrm{PBr}_{3}$ (entry 1, Table 1). To a $50 \mathrm{~mL}$ three-neck flask were added $\delta$-valerolactone $(\mathbf{1 a}$, $5 \mathrm{mmol}$ ) and $\mathrm{PBr}_{3}(5 \mathrm{~mol} \%)$, then $\mathrm{Br}_{2}$ (1.0 equiv) was added dropwise for $2 \mathrm{~h}$ at $0{ }^{\circ} \mathrm{C}$. After adding $\mathrm{Br}_{2}$, another amount of $\mathrm{Br}_{2}$ (1.0 equiv) was added to the reaction mixture for $30 \mathrm{~min}$ at $70{ }^{\circ} \mathrm{C}$. The resulting solution was then stirred for $24 \mathrm{~h}$ at $80{ }^{\circ} \mathrm{C}$. After the reaction was completed, the mixture was dissolved in $\mathrm{CH}_{3} \mathrm{CN}(30 \mathrm{~mL})$ and bubbling $\mathrm{N}_{2}$ gas to remove excess amount of $\mathrm{Br}_{2}$ and the formed $\mathrm{HBr}$ (under open-air) then filtered. The filtrate was concentrated under reduced pressure to produce 2,5dibromopentanoic acid 2a in $90 \%$ yield with trace amount of 1a. The purity of 2 a was determined by ${ }^{1} \mathrm{H}$ and ${ }^{13} \mathrm{C}$ NMR spectroscopy, and 2a was used for the subsequent intramolecular cyclization without any further purification.

General procedure for the synthesis of $\alpha$-substituted lactones 3 via intramolecular cyclization of 2 with $\mathbf{R}_{4} \mathbf{N}^{+} \mathbf{O H}^{-}$ in two-phase system (Table 4 , Table 5 and Scheme $3 \mathrm{~b}$ ). To a $30 \mathrm{~mL}$ flask were added 2 (1.0 mmol, 2a-c: synthesized and used without further purification; 2d: purchased from commercial sources), $\mathrm{CH}_{3} \mathrm{CN}(1.0 \mathrm{~mL}), \mathrm{H}_{2} \mathrm{O}(4 \mathrm{~mL}), \mathrm{CHCl}_{3}(5.0 \mathrm{~mL})$ or MEK $(5.0 \mathrm{~mL})$, and $\mathrm{R}_{4} \mathrm{~N}^{+} \mathrm{OH}^{-}(1.2$ equiv in aqueous solution). The mixture was stirred vigorously at $25{ }^{\circ} \mathrm{C}$ for $1 \mathrm{~h}$. After the reaction was completed, the mixture was extracted with $\mathrm{CHCl}_{3}(15 \mathrm{~mL} \times 3)$. The organic layer was washed with $\mathrm{H}_{2} \mathrm{O}$ $(10 \mathrm{~mL} \times 2)$, dried by anhydrous $\mathrm{Na}_{2} \mathrm{SO}_{4}$, then filtered. The filtrate was concentrated under reduced pressure. Finally, the residue was purified by gel permeation chromatography (eluent: $\mathrm{CH}_{2} \mathrm{Cl}_{2}$ ) or distillation to give pure product 3 .

Gram-scale synthesis of $\alpha$-bromolactone $3 b$ in two-phase system with $\boldsymbol{n}-\mathbf{P r}_{\mathbf{4}} \mathbf{N}^{+} \mathbf{O H}^{-}$(Scheme 3 a). To a $300 \mathrm{~mL}$ flask were added $\mathbf{2 b}$ (10 mmol, synthesized by the procedure above mentioned and used without further purification), $\mathrm{CH}_{3} \mathrm{CN}$ $(10 \mathrm{~mL}), \mathrm{H}_{2} \mathrm{O}(40 \mathrm{~mL}), \operatorname{MEK}(50 \mathrm{~mL})$, and $n-\mathrm{Pr}_{4} \mathrm{~N}^{+} \mathrm{OH}^{-}$ (1.2 equiv in aqueous solution). The mixture was stirred vigorously at $25{ }^{\circ} \mathrm{C}$ for $3 \mathrm{~h}$. After the reaction was completed, the solvent was removed under reduced pressure. The residue was extracted with $\mathrm{CHCl}_{3}(20 \mathrm{~mL} \times 3)$. The organic layer was washed with $\mathrm{H}_{2} \mathrm{O}(10 \mathrm{~mL} \times 2)$, dried by anhydrous $\mathrm{Na}_{2} \mathrm{SO}_{4}$, then filtered. The filtrate was concentrated under reduced pressure. Finally, the residue was purified by distillation to give pure product $3 \mathrm{~b}$ in $64 \%$ yield $(1.05 \mathrm{~g})$.

Cascade synthesis of 5 via two-phase ring closing of $3 \mathrm{~b}$ and following substitution with benzenethiol 4 in the presence of $\mathbf{K}_{\mathbf{2}} \mathbf{C O}_{3}$ (Scheme 4). To a $100 \mathrm{~mL}$ flask were added $\mathbf{2 b}$ (4.0 mmol), $\mathrm{CH}_{3} \mathrm{CN}(4 \mathrm{~mL}), \mathrm{H}_{2} \mathrm{O}(16 \mathrm{~mL})$, MEK (20 mL), and $n-\mathrm{Pr}_{4} \mathrm{~N}^{+} \mathrm{OH}^{-}$(1.2 equiv in aqueous solution). The mixture was stirred vigorously at $25{ }^{\circ} \mathrm{C}$ for $1 \mathrm{~h}$. After the reaction was completed, the mixture was extracted with $\mathrm{CHCl}_{3}(15 \mathrm{~mL} \times 3)$. The organic layer was washed with $\mathrm{H}_{2} \mathrm{O}(10 \mathrm{~mL} \times 2)$, dried by anhydrous $\mathrm{Na}_{2} \mathrm{SO}_{4}$, then filtered. The filtrate was concentrated under reduced pressure to give crude $\mathbf{3 b}$. To a $50 \mathrm{~mL}$ flask were added 3b (used without isolation), benzenethiol 4 (2.4 mmol), DMF $(5 \mathrm{~mL})$, and $\mathrm{K}_{2} \mathrm{CO}_{3}(0.45 \mathrm{mmol})$, and the mixture was stirred at $25{ }^{\circ} \mathrm{C}$ overnight. The resulting mixture was extracted with $\mathrm{CH}_{2} \mathrm{Cl}_{2}(15 \mathrm{~mL} \times 3)$. The organic layer was washed with $\mathrm{H}_{2} \mathrm{O}(10 \mathrm{~mL} \times 2)$, dried by anhydrous $\mathrm{Na}_{2} \mathrm{SO}_{4}$, then filtered. The filtrate was concentrated under reduced pressure. Finally, the residue was purified by silica-gel column chromatography (AcOMe/isohexane) to give pure product 5 .

One-pot synthesis of a functional lactone 6 using $\mathrm{PhS}^{-} \mathrm{Na}^{+}$ as the nucleophiles in the two-phase system (Scheme 6). To a three-necked flask were added $\mathbf{2 a}(2.0 \mathrm{mmol})$, DMSO $(2 \mathrm{~mL})$, $\mathrm{H}_{2} \mathrm{O}(4 \mathrm{~mL}), \mathrm{CHCl}_{3}(10 \mathrm{~mL})$, and $n-\mathrm{Bu}_{4} \mathrm{~N}^{+} \mathrm{OH}^{-}$(1.2 equiv in aqueous solution), and stirred vigorously for $10 \mathrm{~min}$ at $25^{\circ} \mathrm{C}$. Then, a solution of $\mathrm{PhS}^{-} \mathrm{Na}^{+}(1.2 \mathrm{mmol})$ in $\mathrm{H}_{2} \mathrm{O}(4 \mathrm{~mL})$ was slowly added over $30 \mathrm{~min}$. After the addition, the solution was further stirred for $80 \mathrm{~min}$. The resulting mixture was extracted with $\mathrm{Et}_{2} \mathrm{O}(15 \mathrm{~mL} \times 3)$, and the organic layer was washed with $1 \% \mathrm{HCl}$ aq $(10 \mathrm{~mL}), \mathrm{H}_{2} \mathrm{O}(10 \mathrm{~mL} \times 2)$, and dried by anhydrous $\mathrm{MgSO}_{4}$. The filtration was carried out, and the filtrate was concentrated under reduced pressure. Finally, the residue was purified by silica-gel column chromatography $\left(\mathrm{Et}_{2} \mathrm{O} /\right.$ isohexane) to give pure product 6 . 


\section{Supporting Information}

\section{Supporting Information File 1}

Evaluation of the stability of $\alpha$-bromo- $\delta$-valerolactone (3a, Table S1), characterization data of compounds (3a, 3b, 3d, 5, and 6), and copies of ${ }^{1} \mathrm{H}$ NMR and ${ }^{13} \mathrm{C}\left\{{ }^{1} \mathrm{H}\right\}$ NMR spectra.

[https://www.beilstein-journals.org/bjoc/content/ supplementary/1860-5397-17-198-S1.pdf]

\section{Acknowledgements}

The authors would like to express their sincere gratitude to Nippoh Chemicals Co., Ltd. for the collaboration on this project. The authors also acknowledge Mr. Yuta Yabe (Nippoh Chemicals Co., Ltd.) and Ms. Qiqi Chen (Osaka Prefecture University) for the helpful suggestion and experimental support.

\section{Funding}

This research was supported by JSPS KAKENHI (B, 19H02791) and (B, 19H02756), from the Ministry of Education, Culture, Sports, Science and Technology, Japan, and by Kyoto-Advanced Nanotechnology Network.

\section{ORCID ${ }^{\circledR}$ iDs}

Shintaro Kodama - https://orcid.org/0000-0003-4190-9539 Akiya Ogawa - https://orcid.org/0000-0002-8543-2560

\section{References}

1. Hamlin, T. A.; Swart, M.; Bickelhaupt, F. M. ChemPhysChem 2018, 19, 1315-1330. doi:10.1002/cphc.201701363

2. Miyaura, N.; Suzuki, A. Chem. Rev. 1995, 95, 2457-2483. doi:10.1021/cr00039a007

3. Beletskaya, I. P.; Cheprakov, A. V. Chem. Rev. 2000, 100, 3009-3066. doi:10.1021/cr9903048

4. Hassan, J.; Sévignon, M.; Gozzi, C.; Schulz, E.; Lemaire, M. Chem. Rev. 2002, 102, 1359-1470. doi:10.1021/cr000664r

5. Chinchilla, R.; Nájera, C. Chem. Rev. 2007, 107, 874-922. doi:10.1021/cr050992x

6. Surry, D. S.; Buchwald, S. L. Chem. Sci. 2011, 2, 27-50. doi:10.1039/c0sc00331j

7. Kambe, N.; Iwasaki, T.; Terao, J. Chem. Soc. Rev. 2011, 40, 4937-4947. doi:10.1039/c1cs15129k

8. Choi, J.; Fu, G. C. Science 2017, 356, eaaf7230. doi:10.1126/science.aaf7230

9. Koike, T.; Akita, M. Inorg. Chem. Front. 2014, 1, 562-576. doi:10.1039/c4qi00053f

10. Chen, Z.-M.; Zhang, X.-M.; Tu, Y.-Q. Chem. Soc. Rev. 2015, 44, 5220-5245. doi:10.1039/c4cs00467a

11. Studer, A.; Curran, D. P. Angew. Chem., Int. Ed. 2016, 55, 58-102. doi:10.1002/anie.201505090

12. Qiu, G.; Li, Y.; Wu, J. Org. Chem. Front. 2016, 3, 1011-1027. doi:10.1039/c6qo00103c
13. Tan, C. K.; Yeung, Y.-Y. Chem. Commun. 2013, 49, 7985-7996. doi:10.1039/c3cc43950j

14. Saikia, I.; Borah, A. J.; Phukan, P. Chem. Rev. 2016, 116, 6837-7042. doi:10.1021/acs.chemrev.5b00400

15. Petrone, D. A.; Ye, J.; Lautens, M. Chem. Rev. 2016, 116, 8003-8104. doi:10.1021/acs.chemrev.6b00089

16. Das, R.; Kapur, M. Asian J. Org. Chem. 2018, 7, 1524-1541. doi:10.1002/ajoc.201800142

17. Sabuzi, F.; Pomarico, G.; Floris, B.; Valentini, F.; Galloni, P.; Conte, V. Coord. Chem. Rev. 2019, 385, 100-136. doi:10.1016/j.ccr.2019.01.013

18. Phuc Tran, D.; Nomoto, A.; Mita, S.; Dong, C.-p.; Kodama, S.; Mizuno, T.; Ogawa, A. Tetrahedron Lett. 2020, 61, 151959. doi:10.1016/j.tetlet.2020.151959

19. Roy, A.; Biswas, B.; Sen, P. K.; Venkateswaran, R. V. Tetrahedron Lett. 2007, 48, 6933-6936. doi:10.1016/j.tetlet.2007.07.177

20. Baskar, B.; Dakas, P.-Y.; Kumar, K. Org. Lett. 2011, 13, 1988-1991. doi:10.1021/ol200389p

21. Zhao, W.; Lorenz, N.; Jung, K.; Sieber, S. A. Angew. Chem., Int. Ed. 2016, 55, 1187-1191. doi:10.1002/anie.201508052

22. Swapnil, N.; Kumar, A. S.; Babu, N. J.; Yadav, J. S. Asian J. Org. Chem. 2017, 6, 1091-1098. doi:10.1002/ajoc.201700131

23. Panchal, H.; Clarke, C.; Bell, C.; Karad, S. N.; Lewis, W.; Lam, H. W. Chem. Commun. 2018, 54, 12389-12392. doi:10.1039/c8cc06388e

24. Fang, X.-X.; Wang, P.-F.; Yi, W.; Chen, W.; Lou, S.-C.; Liu, G.-Q. J. Org. Chem. 2019, 84, 15677-15684. doi:10.1021/acs.joc.9b02310

25. Tran, Q. T. N.; Wong, W. S. F.; Chai, C. L. L. Eur. J. Med. Chem. 2019, 174, 33-44. doi:10.1016/j.ejmech.2019.04.023

26. Zhao, B.; Li, Z.; Wu, Y.; Wang, Y.; Qian, J.; Yuan, Y.; Shi, Z. Angew. Chem., Int. Ed. 2019, 58, 9448-9452. doi:10.1002/anie.201903721

27. Gu, X.-S.; Yu, N.; Yang, X.-H.; Zhu, A.-T.; Xie, J.-H.; Zhou, Q.-L. Org. Lett. 2019, 21, 4111-4115. doi:10.1021/acs.orglett.9b01290

28. Cholewczynski, A. E.; Williams, P. C.; Pierce, J. G. Org. Lett. 2020, 22, 714-717. doi:10.1021/acs.orglett.9b04546

29. Zeng, F.; Shen, Y.; Zhu, S.; Pelton, R. J. Polym. Sci., Part A: Polym. Chem. 2000, 38, 3821-3827. doi:10.1002/1099-0518(20001015)38:20<3821::aid-pola130>3.0.co;2-g

30. Zhu, L.-W.; Yang, W.; Ou, Y.; Wan, L.-S.; Xu, Z.-K. Polym. Chem. 2014, 5, 3666-3672. doi:10.1039/c4py00101j

31. Olsén, P.; Undin, J.; Odelius, K.; Albertsson, A.-C. Polym. Chem. 2014, 5, 3847-3854. doi:10.1039/c4py00148f

32. Hong, M.; Chen, E. Y.-X. Nat. Chem. 2016, 8, 42-49. doi:10.1038/nchem.2391

33. Becker, G.; Wurm, F. R. Chem. Soc. Rev. 2018, 47, 7739-7782. doi:10.1039/c8cs00531a

34. Song, Q.; Zhao, J.; Zhang, G.; Peruch, F.; Carlotti, S. Polym. J. 2020, 52, 3-11. doi:10.1038/s41428-019-0265-5

35. Price, C. C.; Judge, J. M. Org. Synth. 1965, 45, 22-24. doi:10.15227/orgsyn.045.0022

36. Kamibe, S.; Takahashi, S.; Ichikawa, N. Jap. Patent JP2012167020, 2012.

37. House, H. O.; Czuba, L. J.; Gall, M.; Olmstead, H. D. J. Org. Chem. 1969, 34, 2324-2336. doi:10.1021/jo01260a018

38. Reuss, R. H.; Hassner, A. J. Org. Chem. 1974, 39, 1785-1787. doi:10.1021/jo00925a051

39. Carothers, W. H.; Dorough, G. L.; Natta, F. J. v. J. Am. Chem. Soc. 1932, 54, 761-772. doi:10.1021/ja01341a046

40. Houk, K. N.; Jabbari, A.; Hall, H. K.; Alemán, C. J. Org. Chem. 2008, 73, 2674-2678. doi:10.1021/jo702567v 
41. Zhang, X.; Fevre, M.; Jones, G. O.; Waymouth, R. M. Chem. Rev. 2018, 118, 839-885. doi:10.1021/acs.chemrev.7b00329

42. Ooi, T.; Sugimoto, H.; Maruoka, K. Heterocycles 2001, 54, 593-596. doi:10.3987/com-00-s(i)84

43. Wu, C.-Y.; Brik, A.; Wang, S.-K.; Chen, Y.-H.; Wong, C.-H. ChemBioChem 2005, 6, 2176-2180. doi:10.1002/cbic.200500295

44. Although we tried to isolate $\alpha$-bromo- $\delta$-valerolactone $3 \mathbf{a}$ synthesized by using $n-\mathrm{Pr}_{4} \mathrm{~N}^{+} \mathrm{OH}^{-}$as the base (entry 1 in Table 4), 3a was very unstable and some decomposition of $\mathbf{3 a}$ was observed during the isolation using a recycling GPC (eluent: $\mathrm{CH}_{2} \mathrm{Cl}_{2}$ ). Finally, we could be isolated pure $3 \mathbf{a}$ in $20 \%$ yield. The details of the stability of $3 a$ under ambient conditions and the characterization data of $\mathbf{3} \mathbf{a}$ are given in Supporting Information File 1.

45. Trost, B. M.; Mao, M. K.-T.; Balkovec, J. M.; Buhlmayer, P. J. Am. Chem. Soc. 1986, 108, 4965-4973. doi:10.1021/ja00276a043

46. Carretero, J. C.; Rojo, J.; Díaz, N.; Hamdouchi, C.; Poveda, A. Tetrahedron 1995, 51, 8507-8524. doi:10.1016/0040-4020(95)00453-f

47. Sabbah, M.; Bernollin, M.; Doutheau, A.; Soulère, L.; Queneau, Y. Med. Chem. Commun. 2013, 4, 363-366. doi:10.1039/c2md20298k

48. Zhang, X.; Wu, J.; Liu, Y.; Xie, Y.; Liu, C.; Wang, J.; Zhao, G. Phosphorus, Sulfur Silicon Relat. Elem. 2017, 192, 799-811. doi:10.1080/10426507.2017.1286492

\section{License and Terms}

This is an open access article licensed under the terms of the Beilstein-Institut Open Access License Agreement (https://www.beilstein-journals.org/bjoc/terms), which is identical to the Creative Commons Attribution 4.0 International License

(https://creativecommons.org/licenses/by/4.0). The reuse of material under this license requires that the author(s), source and license are credited. Third-party material in this article could be subject to other licenses (typically indicated in the credit line), and in this case, users are required to obtain permission from the license holder to reuse the material.

The definitive version of this article is the electronic one which can be found at:

https://doi.org/10.3762/bjoc.17.198 